\title{
DESIGN AN ELECTRONIC ENABLED ORGANIC COTTON HOUSE SLIPPER FOR FOOT REFLEXOLOGY TREATMENT
}

\author{
CHANDRASEKAR .S, ABISHA .S,ELANCHEZHIYAN .M, JEYSANKAR .M
}

\begin{abstract}
Reflexology is gentle manipulation or pressing on certain parts of the foot, hand and ears to produce an effect elsewhere in the body. It stems from traditional Chinese medicine. "The idea is that energy, called 'chi' flows through the body along particular pathways, or meridians" says Denis Merkas, an acupuncturist and massage therapist. The idea of this article is to provide reflexology treatment for the foot by designing a pair of organic cotton house slipper in which electronically controlled airbags are incorporated at the flat surface. This helps to stimulate the circulation of the blood, helping muscle tone, results in enhancing the calmness and relaxing effects of a foot massage on the whole body.
\end{abstract}

Keywords: Reflexology, Solenoid Valves.

\section{INTRODUCTION}

In the modern days, the working people in their busy schedule they forget to take care of their health. Most office workers spend a large amount of their day sat at a desk have aches and pains in their back, especially their lower spine. Stress is a number one issue for workers in many jobs, and people in an office are no exception. Reflexology treatment can provide a better way working people to restore their natural balance. The ancient Chinese practice of reflexology, a manual therapy focusing on the feet, has recently enjoyed a surge in popularity as a modern holistic therapy to relieve pain and stress, to improve circulation, and restoring natural balance. With the idea of this paper, people can get the effects of reflexology at home.

\section{OVERVIEW OF REFLEXOLOGY TREATMENT}

Reflexology promotes healing by stimulating the nerves in the body and encouraging the flow of blood. In the process, reflexology not only quells the sensation of pain, but relieves the source of the pain as well. There is a term in reflexology called reflex zone therapy. Reflex zone therapy is where the body is divided into ten longitudinal zones from head to toe. There are five theories that support how reflexology gives impacts to body health. First and second basic theories are related to energy. Energy theory advocates that body parts can communicate using electromagnetic fields and the communication can be blocked based on the surrounding respectively. Third and fourth theories indicate that energy flow can be restored and the fourth is about the pathway which is blocked can be opened. The last theory proposes that reflexology can break up the lactic acid crystal that usually deposited in the feet and allow energy to flow efficiently. Based on latest research conducted, reflexology seems to be effective in helping the body systems to return to its natural state. The most significant current discussions in reflexology practice are related to the aspect of health, safety, and hygiene. Other than that, the principles and practice of reflexology as a complementary therapy is important to make sure the application of this therapy is reliable.

\section{SCIENCE OF REFLEXOLOGY}

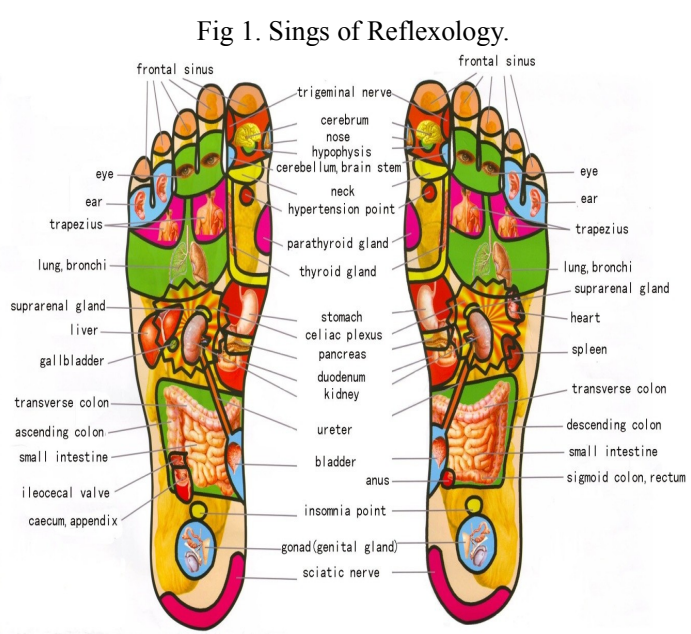

Both Reflexology and Acupressure fall into the category of touch therapies called Reflex Therapies. However, they each work under very different energetic principles and extremely different reflex point locations.

Acupressure deals with over 14 long thin energy lines called meridians that run most of the length of the body. There are more than 800 pressure points along these lines of which, fewer than 30 are found on the feet and the hands with only one meridian acupressure point on the bottom of the feet, and only one meridian even coming close to the ear, in the crease behind the outer ear.

Reflexology, in contrast, has an entire reflex map of the body on the feet, a second complete reflex map of the body on the hands and a third complete reflex map of the body on the outer ear.

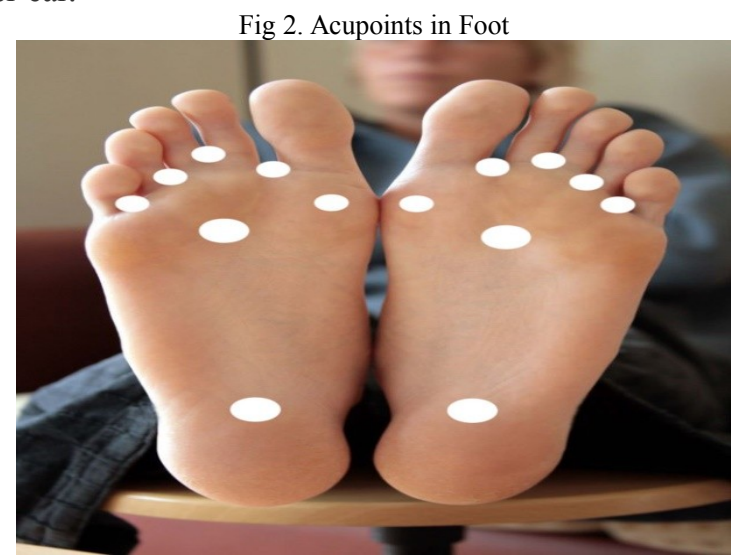




\section{Asian Journal of Convergence in Technology ISSN NO: 2350-1146 I.F-5.11}

Out of these, we have considered seven different points separately on both the legs. The first point is hypertension point which is considered because it is directly responsible for $57 \%$ of all stroke deaths and $24 \%$ of all coronary heart disease deaths in India. The second is insomnia point is taken to reduce the depression of the people. The third point corresponding to lungs is considered. The remaining points are discussed below.

Table I. The relationship of left side of reflex zone with its corresponding

\begin{tabular}{|c|c|}
\hline \multicolumn{2}{|c|}{ organs. } \\
\hline $\begin{array}{c}\text { Reflex zone } \\
\text { Corresponding organs } \\
\text { second toe }\end{array}$ & $\begin{array}{c}\text { Brain, eye, adenoids, } \\
\text { lungs, heart, stomach, } \\
\text { spleen, pancreas, breast, } \\
\text { small and large intestine }\end{array}$ \\
\hline $\begin{array}{c}\text { Left middle finger and } \\
\text { third toe }\end{array}$ & $\begin{array}{c}\text { Brain, eye, lung, breast, } \\
\text { stomach, spleen, pancreas, } \\
\text { kidney, adrenal gland, } \\
\text { small and large intestine }\end{array}$ \\
\hline $\begin{array}{c}\text { Left ring finger and fourth } \\
\text { toe }\end{array}$ & $\begin{array}{c}\text { Brain, eye, lungs, breast, } \\
\text { large intestine, ovaries }\end{array}$ \\
\hline $\begin{array}{c}\text { Left little finger and fifth } \\
\text { toe }\end{array}$ & Ear \\
\hline
\end{tabular}

Table II. The relationship of right side of reflex zone with its corresponding

\begin{tabular}{|c|c|}
\hline Reflex zone & Corresponding organs \\
\hline $\begin{array}{c}\text { Right index finger and } \\
\text { second toe }\end{array}$ & $\begin{array}{c}\text { Brain, eye, lung, breast, } \\
\text { liver, small and large } \\
\text { intestine, adenoids }\end{array}$ \\
\hline $\begin{array}{c}\text { Right middle finger and } \\
\text { third toe }\end{array}$ & $\begin{array}{c}\text { Brain, eye, breast, liver, } \\
\text { gall bladder, kidney, small } \\
\text { and large intestine, adrenal } \\
\text { gland }\end{array}$ \\
\hline $\begin{array}{c}\text { Right ring finger and } \\
\text { fourth toe }\end{array}$ & $\begin{array}{c}\text { Brain, eye, main } \\
\text { lymphatic duct, breast, } \\
\text { liver, lung, large intestine, } \\
\text { ileo-cecal valve, appendix }\end{array}$ \\
\hline $\begin{array}{c}\text { Right little finger and } \\
\text { fourth toe }\end{array}$ & Ear \\
\hline
\end{tabular}

\section{BENEFITS OF REFLEXOLOGY}

Reflexology has been chosen by most people to treat their body health problems because it offers high level of safety and effectiveness. It also offers natural treatment without consuming drugs and it is easy to use. Learning reflexology and its application is quite easy, there is no limitation for people to apply it anytime and anywhere. Its effectiveness in treating the root of some diseases may lead to many benefits in health concern such as it helps in easing day-to-day stresses and illness. Reflexology is one of the ways to interrupt the pattern of repetitive stress that people usually have according to their lifestyle.

\section{DESIGN}

Today, popularity of reflexology is increasing everywhere. But not everybody have the knowledge of exact reflexology zones, so does it mean people who lack in this knowledge cannot acquire an efficient reflexology treatment by themselves. The protocol is designed in such a way to serve

\section{Volume V Issue I}

the foot massage by reflexology by just wearing the electronically designed house slipper while taking rest.

\section{BLOCK DIAGRAM}

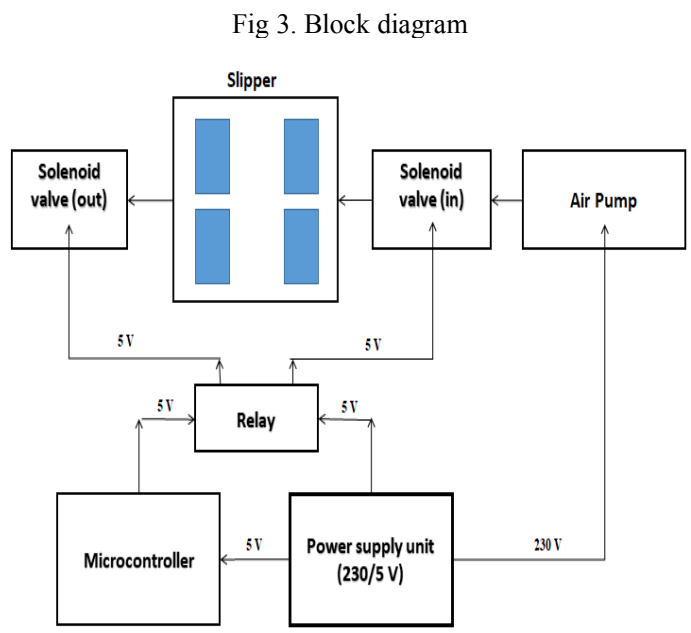

VII. TECHNICAL ASPECT

1) The Controlling Part:

A power supply board is designed using a step down transformer $(230 \mathrm{~V} / 12 \mathrm{~V})$, rectifier and a IC7805 regulator to get $5 \mathrm{~V}$ regulated supply. The regulated $5 \mathrm{~V}$ is used to operate microcontroller and relays. The stepped down voltage of $12 \mathrm{~V}$ is given as supply to the solenoid valves. $230 \mathrm{~V}$ operated electric air pump is used to suck and pump the atmospheric air. The output of the pump is connected to the inlet of the solenoid valve. The relay and the solenoid valves are controlled by the microcontroller. The solenoid valve is connected with hoses to provide air to the airbags incorporated onto the cotton house slipper.

\section{2) The Hardware Part:}

A pair of organic cotton house slipper is designed with few layers of cotton in which the airbags are kept. Because cotton will be pre - compressed and hand tufted to ensure a consistent feel and genuine luxurious comfort. It is also great at wicking moisture and it is hypoallergenic. The airbags have square shaped base above which a balloon like projection will be there. Seven points are considered in both the foot where the airbags are placed. Each of the airbags is provided with an inlet and an outlet. The inlets are connected to solenoid valves through hose and the outlets are opened into the atmosphere through solenoid valve.

\section{3) Cotton Sandal Model and Working:}

Fig 4. Cross sectional view

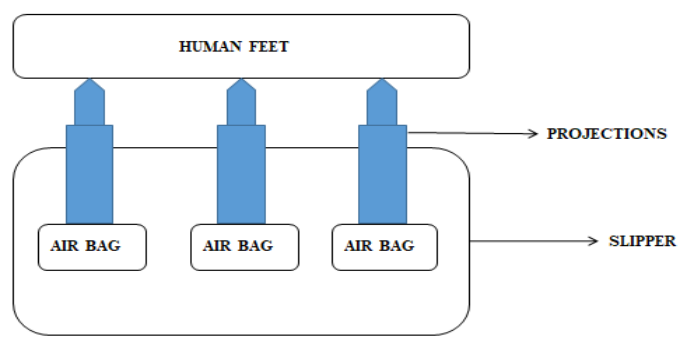

CROSS SECTIONAL VIEW 


\section{Asian Journal of Convergence in Technology ISSN NO: 2350-1146 I.F-5.11}

When the power supply board is given with $230 \mathrm{~V}$ supply, the microcontroller gets $5 \mathrm{~V}$ supply and the work starts as programmed. The reflexology time did not exceed $30 \mathrm{~min}$. The treatment was administered to the left foot and then the right foot (15 min each). Accordingly, in the microcontroller is programmed to operate the airbags one by one in left sandals for 15 minutes and then the airbags in the right sandals get operated for 15 minutes. Firstly the relay operates in NORMALLY ON mode, hence the inlet regulating solenoid valve opens for 5 seconds (i.e., for 5 seconds the projection is extended). After that the relay operates at NORMALLY OFF mode for 3 seconds by regulating the outlet connected solenoid valve. It is programmed to operate the airbags one after the other at a regular interval of time or particularly to one airbag as per the need. When air enters the airbag, it enlarges by which projection moves upward and hence it presses the particular surface of the palm.

\section{CONCLUSION}

Reflexology practitioners and the professional association have advocated that reflexology is effective for general wellbeing maintenance and treatment of chronic diseases such as strokes, musculoskeletal disorders, and stress. Due to its soothing massage and non-drug complementary nature, reflexology is widely accepted by general public.

\section{REFERENCES}

[1] Somya Gupta, Aman Malhotra, "Active Reflexology Actuation And Pressure Mapping Footwear", 2018 5th IEEE Uttar Pradesh Section International Conference On Electrical, Electronics And Computer Engineering (UPCON).

[2] Gan-Hon Lin, Wei-Chun Chang, Kuan-Ju Chen, ChenChen Tsai, Sung-Yuan Hu and Li-Li Chen, "Effectiveness of Acupressure on the Taichong Acupoint in Lowering Blood Pressure in Patients with Hypertension: A Randomized Clinical Trial", Evid Based Complement Alternat Med. 2016; 2016: 1549658

[3] Raghupathy Anchala, Nanda K. Kannuri, Hira Pant, Hassan Khan, Oscar H. Franco, Emanuele Di Angelantonio And Dorairaj Prabhakaran, "Hypertension In India: A Systematic Review And Meta-Analysis Of Prevalence, Awareness, And Control Of Hypertension", Journal Of Hypertension 2014 Jun; 32(6): 1170-1177.

[4] Wojciech Kobza, Pawel Lizis, Halina Romualda Zięba, "Effects Of Feet Reflexology Versus Segmental Massage In Reducing Pain And Its Intensity, Frequency And Duration Of The Attacks In Females With Migraine: A Pilot Study Author Links Open Overlay Panel", Journal Of Traditional Chinese Medicine Volume 37, Issue 2, April 2017, Pages 214-219.

[5] Yingbao Zhao ; Xue-Ling Song ; Chao-Ying Liu ; ZheYing, "Solenoid Valve Respond Time Test System Basing On

\section{Volume V Issue I}

Single Chip Micro-Computer", Song-2009 International Conference On Intelligent Human-Machine Systems And Cybernetics.

[6] David O'Regan, Christopher J Kenyon, Jonathan R Seckl And Megan C Holmes, "Prenatal Dexamethasone 'Programmes' Hypotension, But Stress-Induced Hypertension In Adult Offspring”, In Journal Of Endocrinology Volume 196: Issue 2, Page 343-352, Feb 2008.

[7] Kunz B. 2003. "Reflexology Health at Your Fingertips: Hands-on Treatment for Vitality and Well-being"; p. 160

[8] Traditional and Complementary Medicine Division . Ministry of Health Malaysia; 2011. Practice Guideline on Reflexology for Reflexologist Practicing in Malaysia. http://tcm.moh.gov.my/v4/pdf/guideline/GPGOnReflexology 2011.pdf Available from: Accessed 03.05.15.

[9] Rajarajan Ramalingam, Zheng Hu, Carina Gerlach, Olfa Kanoun, "Shoe Insole with MWCNT-PDMS-Composite Sensors for Pressure Monitoring".

[10] Ziad O. Abu-Faraj, "Leg Length Discrepancy: A Study on In-Shoe Plantar Pressure Distribution", Ph.D.§, IEEE Senior MemberMohamed M. Abdul-Al, B.S., IEEE Student Member.

[11] Patrick C, Connor ViTRAK Systems Inc "Comparing and Combining Underfoot Pressure Features for Shod and Unshod Gait Biometrics", 2015 IEEE International Symposium on Technologies for Homeland Security (HST)

[12] Kunz K., Kunz B. Understanding the science and art of reflexology. Altern Complement Ther. 1995;1:183-186.

[13] Blunt E. Foot reflexology. Holist Nurs Pract. 2006;20:257-259.

[14] Zhaoqin Peng1*, Guowei Ma, Jiayue Li, "Human falling recognition system design with wearable pressure sensing shoes", 2017 12th IEEE Conference on Industrial Electronics and Applications (ICIEA).

[15] Xavier R. Facts on reflexology (foot massage) Nurs J India. 2007;98:11-12.

[16] Cade M. “Reflexology”, Kans Nurse. 2002;77:5-6. 